\title{
Constructing an Evaluation Indicator System for Sustainable Fashion
}

\author{
Hongshan Zhao ${ }^{*}$ and Huanjie Wang
}

\author{
School of Business, Beijing Institute of Fashion Technology \\ *Corresponding author.Email: sxyzhs@bift.edu.cn
}

\begin{abstract}
In light of the industry's vague understanding of sustainable fashion and the emergence of such problem as greenwashing. On the basis of the collation of industry's information, 23 experts screen and optimize sustainable fashion evaluation indicators by the Delphi method. The result is an evaluation indicator system comprising 5 tier-1 indicators and 20 tier- 2 indicators. The tier- 1 indicators cover the entire lifecycle of fashion products and include sustainable design, sustainable procurement, sustainable production, sustainable sale, and sustainable recycling. The tier-2 indicators are determined with reference to the GRI indicator system and the Higg indicator system as well as the opinions of industry experts. Moreover, this paper calculates the weight of various indicators by way of the analytic hierarchy process with a view to quantitatively identifying the relative weight of all indicators. The result indicates that the tier-1 indicator "sustainable production" has the greatest impact on the evaluation of sustainable fashion and that the tier-2 indicators "green transportation means" and "packaging materials re-utilization" have relative greater weight.
\end{abstract}

Keywords: Sustainable fashion, Evaluation indicator system, Delphi method, Analytic hierarchy process.

\section{INTRODUCTION}

The environment issue has become a global headache in recent years. The textile industry, in particular, is considered the principal perpetrator of the marine plastic pollution across the world (Yang, 2018) [1]. In the context of stark environmental pollution, it is imperative for the textile and fashion industries to seek a sustainable development path. However, there are no officially published evaluation tools for sustainable fashion at present; and different enterprises have different understanding of it. The term "sustainable fashion" can be traced back to the concept "fashion and sustainable development" put forth at a United Nations Department of Public Information/Non-Governmental Organizations conference. During the 1980s and the 1990s, the western fashion community launched an antifur movement; Kate Fletcher, an important figure in the fashion theory field, founded a Research Center for Slow Fashion and Sustainable Design and made her own interpretation on sustainable fashion (Jung \& Jin, 2014) [2]. As the industry paid increasing attention to sustainable fashion, domestic and foreign scholars began to research sustainable design, procurement, production, marketing and more. The results of these theoretical researches and industry practices have all helped to lay a theoretical foundation and provide reference for this paper. Nonetheless, little research has been done on the lifecycle of fashion products and academic research on sustainable fashion evaluation indicators is also found wanting.

This paper first formulates an outline of sustainable fashion evaluation indicators in reference to existing indicators, then constructs a preliminary indicator system covering the lifecycle of fashion products by screening the indicators following the Delphi method, and finally works out the relative weights of indicators on various tiers through the analytic hierarchy process. It aims to provide recommendation and reference for fashion businesses to pursue sustainable development.

\section{OVERVIEW OF SUSTAINABLE FASHION}

\subsection{Summary of Sustainable Fashion Theories}

In an effort to construct a better evaluation indicator system for sustainable fashion, we must define sustainable fashion in the first place. This paper follows Fletcher's understanding of sustainable fashion that it is 
affected by all links of the fashion production. Accordingly, this paper defines sustainable fashion as a series of environment-friendly behaviors of developing and producing fashion products based on the supply chain and across the lifecycle of fashion products. Specifically, sustainable fashion means to design, procure raw materials for, produce, market and recycle clothing, shoes and hats and accessories, among others, in a sustainable manner, and take into account the environmental, social and economic impact of the entire process.

Domestic and foreign researches on sustainable fashion focus on such perspectives as sustainable design, sustainable procurement, sustainable production, sustainable consumption, sustainable recycling and so on. Regarding sustainable design and procurement, Niinimaki and Koskinen (2011) point out the possibility of promoting sustainable development through extending the lifecycle of fashion products [3]. Sustainable design finds expression mainly in the application of design principles and methods. For instance, Canadian designer Amelie Mongrain proposed the 6R sustainable design principle, and domestic scholar JIA Shujie (2018) renovates used clothes by researching design methods for fashion restructuring and reuse [4]. In respect of sustainable procurement, Jørgensen points out that enterprises can alter the entire supply chain by working on such driving forces as the companies themselves, the suppliers and the markets, thus promoting sustainable development [5]. Željko STEVIĆ (2019) applies the fuzzy analytic hierarchy process to evaluate suppliers, focusing on sustainability evaluation mechanisms and supplier selection strategies [6]. When it comes to sustainable production, domestic scholar XUE Yang constructs four tier-1 indicators, namely, green R\&D capability, green production capability, green product recognition and green cultural capability, to evaluate textile enterprises' performance in green production and makes some case analyses based on the grey relation analysis method [7]. In sustainable sale terms, Elsasser (2011) researches the impact of sustainable consumption on the development of sustainable fashion from the consumer behavioral perspective, while ZHU Mingyang and LIN Zihua (2015) preliminarily examine the motivation of business models for sustainability and look into the trends of future development [8]. So domestic and foreign scholars have discussed sustainability theories for sustainable fashion by looking at different dimensions and therefore laid theoretical foundations for this paper.

\subsection{Status Quo of Sustainable Fashion}

In respect of industry organizations' or associations' efforts, the United Nations headquarters in New York
City has put on a unique environment-friendly fashion show as early as in 2017 to induce in-depth thinking on sustainable fashion and social development in general. The Global Fashion Agenda based in Copenhagen and Boston Consulting Group jointly released the Pulse of the Fashion Industry report in 2017. The report directly pointed out the business opportunities that would be brought about to the fashion industry by sustainable development. In addition, the Sustainable Apparel Coalition (SAC) proposed the sustainability evaluation tool, i.e. Higg Index, from environmental perspective; and the Global Reporting Initiative (GRI) set out sustainability reporting guidelines from economic, environmental and social perspectives, offering enterprises an important tool to conduct triple performance appraisal.

In terms of corporate practice, Kering developed the evaluation tool EP\&L that measures and quantifies the environmental impact of its operating activities. The Swedish fast fashion mogul H\&M developed a comprehensive sustainability strategy in 2017 to champion sustainability by informing sustainable practices on the part of the industry, achieving environment-friendly circular production and fair development, and publishing sustainable development reports on a yearly basis. On the other hand, domestic business Ruyi Group signed the Fashion Pact together with 32 other fashion and textile heavyweights from all over the world; JNBY launched the sustainable brand REVERB in the theme of zero waste in 2018; and the fashion rental APP "Ycloset", which practices sustainable business models, has also emerged on the Chinese market.

\section{SELECTION OF SUSTAINABLE FASHION EVALUATION INDICATORS}

\subsection{Analyses of Evaluation Indicators}

An evaluation indicator system is an organic whole with an inherent structure composed of several indicators that characteristically evaluate various aspects of an object and the correlations between them. The relatively more comprehensive sustainability evaluation indicator systems widely adopted across the world at present include the GRI and Higg Index systems. In addition, there are some more targeted evaluation standards, such as the green eco-label Oeko-Tex Standard 100, the blue eco-label and other third party certification standards. These evaluation indicator systems are of great referential value to the construction of the sustainable fashion evaluation indicator system in this paper. 
Table 1. Proposed indicators for sustainable fashion

\begin{tabular}{|c|c|c|c|}
\hline Goal & Guideline level & Indicator level & Domain \\
\hline \multirow{28}{*}{ 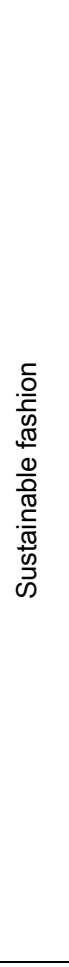 } & \multirow{6}{*}{ Sustainable design } & Raw materials utilization & \multirow{2}{*}{ Low energy consumption design } \\
\hline & & Processability & \\
\hline & & Product recyclability & Durable design \\
\hline & & Product degradability & Environment-friendly design \\
\hline & & Share of renewable materials & \multirow{2}{*}{ Raw materials } \\
\hline & & Share of recyclable materials & \\
\hline & \multirow{7}{*}{ Sustainable procurement } & Share of suppliers selected based on & \multirow{4}{*}{ Suppliers } \\
\hline & & Recognition of supplier's greening & \\
\hline & & Share of renewable energy used & \\
\hline & & Waste water produced & \\
\hline & & GHG emissions & \multirow{3}{*}{ Clean production capability } \\
\hline & & Noise level & \\
\hline & & Solid waste emissions & \\
\hline & \multirow{9}{*}{ Sustainable production } & Energy-saving equipment utilization & \multirow{4}{*}{ Low-consumption production capability } \\
\hline & & Ratio of water intake to water discharge & \\
\hline & & Energy consumption reduced & \\
\hline & & Water use reduced & \\
\hline & & Share of sustainable product developed & \multirow{3}{*}{ Innovative production capability } \\
\hline & & Number of sustainable processes patented & \\
\hline & & Share of R\&D expenditure for sustainable & \\
\hline & & Packaging materials re-utilization & Packaging \\
\hline & & Share of green transportation means & Transportation \\
\hline & \multirow{3}{*}{ Sustainable sale } & Profitability of sustainable products & \multirow{3}{*}{ Marketing } \\
\hline & & Sales-production ratio & \\
\hline & & Brand recognition & \\
\hline & \multirow{3}{*}{ Sustainable recycling } & Used products re-utilization & Product recycling \\
\hline & & Overall re-utilization of waste water, gas and & waste water, gas and materials \\
\hline & & Harm-free waste disposal cost & Cost \\
\hline
\end{tabular}

Particularly, the GRI indicator system refers to the sustainability reporting Guidelines proposed by the Global Reporting Initiative. It is not only an important guide for disclosing information on social responsibility, but also an important tool for enterprises to conduct economic, environmental and social performance appraisal. The Higg Index system is a basic instrument of great importance for the apparel industry. It is primarily used to measure and evaluate the environment-friendliness of enterprises on all levels and across the supply chain, such as brand owners, factories and products. It is an innovative self-evaluation tool.

\subsection{Formulation of the Indicator System}

Based on collation and analyses of existing indicator systems, the author finds that evaluation tools capable of evaluating sustainability relatively more comprehensively are quite few today. However, the industry is attempting to construct more suitable evaluation tools for sustainable fashion. For example, with reference to many existing industry standards, the SAC is developing sustainable fashion evaluation indicators which make it easier for customers to evaluate the sustainability of brands, manufacturers and particular products. In reference to the foregoing indicators, this paper divides the indicators covering the lifecycle of fashion products into three levels. The top level indicator is sustainable fashion, which is the goal; the second level includes sustainable design, sustainable procurement, sustainable production, sustainable sale, and sustainable recycling, which are guidelines; and the third level includes specific indicators. The system is shown in Table 1 below.

\section{CONSTRUCTION OF THE EVALUATION INDICATOR SYSTEM FOR SUSTAINABLE FASHION}

\subsection{Principles and Methods of Construction}

The evaluation of sustainable fashion involves many indicators. In a bid to construct a scientific and reasonable sustainability evaluation indicator system, this paper is composed on the basis of science-based, comprehensive, representative and applicable principles. Moreover, indicators have been screened and optimized by the Delphi method. The key steps in implementing the Delphi method include: establishing an expert group; identifying questions and formulating questionnaires; distributing questionnaires; collecting and collating anonymous questionnaire data; making feedback; and making inquiries again. Specifically, this paper designs two different questionnaires: "construction of evaluation indicators for sustainable fashion - questionnaire for experts (round 1 and round 2)" and "identification of weights for sustainable fashion evaluation indicators questionnaire for experts". On a 5-point Likert Scale, the questionnaires requested experts to score various indicators in terms of their importance in order to measure the reasonableness of the chosen indicators. Meanwhile, the reliability of data was measured according to "the basis on which experts make their 
Table 2. Preliminary evaluation indicator system for sustainable fashion

\begin{tabular}{|c|c|c|}
\hline Goal level & Guideline level & Indicator level \\
\hline \multirow{20}{*}{ 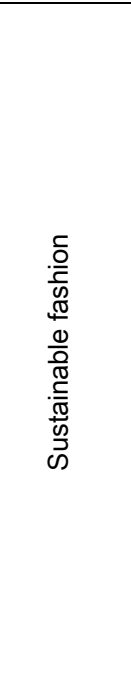 } & \multirow{4}{*}{ Sustainable design (A) } & Materials utilization (A1) \\
\hline & & Processability (A2) \\
\hline & & Average service life (A3) \\
\hline & & Degradability (A4) \\
\hline & \multirow{4}{*}{ Sustainable procurement (B) } & Share of environment-friendly materials (B1) \\
\hline & & Share of suppliers selected based on environmental standards (B2) \\
\hline & & Transparency of procurement (B3) \\
\hline & & Recognition of supplier's greening (B4) \\
\hline & \multirow{5}{*}{ Sustainable production $(\mathrm{C})$} & Waste water produced (C1) \\
\hline & & GHG emissions (C2) \\
\hline & & Energy-saving equipment utilization (C3) \\
\hline & & Energy consumption reduced (C4) \\
\hline & & Water use reduced (C5) \\
\hline & \multirow{4}{*}{ Sustainable sale (D) } & Share of green transportation means (D1) \\
\hline & & Packaging materials re-utilization (D2) \\
\hline & & Share of sustainable products developed (D3) \\
\hline & & Brand recognition (D4) \\
\hline & \multirow{3}{*}{ Sustainable recycling $(E)$} & Used products re-utilization (E1) \\
\hline & & Overall re-utilization of waste water, gas and materials (E2) \\
\hline & & Harm-free waste disposal cost (E3) \\
\hline
\end{tabular}

judgements" and "the familiarity of experts with the content surveyed".

To implement the Delphi method, the author established an expert group made up of 23 people, including 8 experts (5 professors and 3 postgraduate students majoring in fashion design) from Beijing Institute of Fashion Technology and 15 industry experts (5 designers and 10 marketing and operating personnel). The questionnaires were mainly emailed or sent online to respondents. The experts were all informed of the research purpose, the questionnaire completion requirements and the collection deadline before questionnaire distribution. To screen indicators, the author conducted two rounds of inquiry with the experts and stopped distributing more questionnaires when they reached an over $80 \%$ consensus.

\subsection{Establishing the Preliminary Indicator System}

Collation and analyses of the questionnaire data generated the following results: in respect of experts' enthusiasm, all experts responded the questionnaires within the stipulated time frame, with the effective response rate standing at $100 \%$ for both rounds of inquiry. In terms of the convergence of experts' opinions, the average scores of all indicators ranged from 3.88 to 4.79 in the first round of inquiry and from 3.88 to 4.78 in the second round (with the full score being 5) and the full score frequency ranged between 0.39 and 0.87 in the first round and between 0.43 and 0.8 in the second. The coefficients of variation were all lower than 0.05 in the first round of inquiry, indicating that experts' opinions were somewhat divided in the first round of questionnaire response. However, their opinions became relatively more converged in the second round after revision, thus meeting the convergence requirement. Regarding experts' authority, as measured by the formula $(C R)=\frac{C a+C_{s}}{2}$, in which $\mathrm{Ca}$ represents the basis on which experts made their judgments and Cs the familiarity of experts with the indicators, the $\mathrm{CR}$ value stood at 0.77 and 0.78 respectively in the two rounds of inquiry, both exceeding 0.7 and indicating reliability of the inquiry results.

After two rounds of inquiry with experts, opinions tended to converge. The indicators "noise level", "share of renewable energy used", "solid waste emissions", "ratio of water intake to water discharge", "share of R\&D expenditure for sustainable production technologies", "profitability of sustainable products", "average sales-production ratio" and "number of sustainable processes patented" were deleted because their average value $\mathrm{Mj}$ was lower than 0.4 and their full score frequency $\mathrm{Kj}$ was lower than 0.5. Through discussion and consulting with experts, the indicators "share of renewable materials" and "share of recyclable materials" were merged into the indicator "share of environment-friendly materials"; and the indicator "share of sustainable products developed" was included under the tier-1 indicator "sustainable sale". In the end, a sustainable fashion evaluation indicator system comprising 5 tier- 1 indicators and 20 tier- 2 indicators was constructed. The preliminary indicator system was shown in Table 2. 


\section{QUANTITATIVE ANALYSES OF THE SUSTAINABLE FASHION EVALUATION INDICATOR SYSTEM}

\subsection{Quantitative Analysis Steps in the Analytic Hierarchy Process}

The AHP method breaks down a complicated problem into several hierarchies, oftentimes the overall goal level, the solution level, the sub-goal level and the guideline level, then establishes judgment matrixes to look into the importance of a particular sub-element on a level to the parent element, and finally obtains the weight of various elements by mathematical means. Drawing on Saaty's ratio scale method (1980), this study had experts (fashion industry insiders, scholars, sustainability certification organizations' personnel, etc.) score every indicator in terms of their importance to other indicators and constructed a judgment matrix for every indicator level. In this way, a total of 6 judgment matrixes were established and presented as $\mathrm{C} 1-\mathrm{P}, \mathrm{C} 2-\mathrm{P}$, C3-P, C4-P, C5-P and C6-P respectively. It is clear that pii $=1, \quad \mathrm{i}=\mathrm{j} ; \mathrm{pij}=1 / \mathrm{pji}, \mathrm{i} \neq \mathrm{j}$. Take the matrix $\mathrm{C} 1-\mathrm{P}$ for instance:

$$
C_{1}-P=\left[\begin{array}{ccccc}
1 & p_{12} & p_{13} & p_{14} & p_{15} \\
p_{21} & 1 & p_{23} & p_{24} & p_{25} \\
p_{31} & p_{32} & 1 & p_{34} & p_{35} \\
p_{41} & p_{42} & p_{43} & 1 & p_{45} \\
p_{51} & p_{52} & p_{53} & p_{54} & 1
\end{array}\right]
$$

Figure 1. The matrix C1-P.

The next step is single hierarchical arrangement to calculate $\lambda \max$, the maximum eigenvalue of each judgment matrix, as well as $\varpi \mathbf{i}$, the corresponding eigenvectors. This paper adopts the square root method to do the calculations abovementioned. The last step is the consistency test. It is generally believed that when $\mathrm{CR}$ is lower than 0.1 , the results of calculations in the single hierarchical arrangement step complies with the requirements of the consistency test. Otherwise, there is the need to adjust values of various indicators in a judgment matrix, do the calculations again and make the total taxis of hierarchy in the end.

\subsection{Data Collection and Weight Calculation}

In the weight assignment stage, this paper distributed questionnaires to 12 experts "familiar with sustainable fashion" selected from the expert group and collected 12 effective responses. Therefore, 6 judgment matrixes were created. Take the judgment matrix C1-P for instance. According to the formula $M_{\mathrm{i}}=\prod_{i=1}^{5} p_{\mathrm{ij}}$, the following results can be obtained: $\mathrm{M} 1=13.5$; $\mathrm{M} 2=0.2222 ; \mathrm{M} 3=72 ; \mathrm{M} 4=0.0208 ; \mathrm{M} 5=0.2222$. Based on the formula $\omega_{\mathrm{i}}=\sqrt[n]{M_{\mathrm{i}}}$, the following results can be arrived at:

$$
\begin{aligned}
& \omega_{1=1.6829 ;} \omega_{2}=0.7402 ; \omega_{3}=2.3522 ; \omega_{4}=0.4611 ; \\
& \omega_{5}=0.7402 .
\end{aligned}
$$

The formula ${ }^{\sigma_{i}}=\frac{\omega_{i}}{\sum_{i=1}^{n} \omega_{i}}$ can then be used to normalize the vectors $\omega=\left(\omega_{1,}, \omega_{2}, \omega_{3}, \ldots, \omega_{n}\right)$ and results in $\omega_{\mathrm{i}}$ $=(0.2816,0.1239,0.3936,0.0771,0.1239) \mathrm{T}$. Similarly, the calculation results for other judgment matrixes can be obtained using Excel as shown in the following tables from Table3 to Table7.

Generally speaking, when CR is lower than 0.1 , the results of calculations in the single hierarchical arrangement step complies with the requirements of the consistency test. The results of the consistency test for single hierarchies can be arrived at by using the formulas $C R=\frac{C I}{R I}$ and $C I=\frac{\lambda_{\max }-n}{n-1}$ and consulting the CI values, as shown in Table 8.

The table indicates clearly that the $\mathrm{CR}$ for each judgment matrix is smaller than 0.1, thus passing the consistency test. Accordingly, the weights for sustainable fashion evaluation indicators on various levels can be obtained, as shown in Table 9.

\section{CONCLUSIONS AND OUTLOOK}

This paper formulates a sustainable fashion evaluation indicator system covering the lifecycle of fashion products based on the Delphi and AHP methods. From the weights of various indicators for sustainable fashion, we can see that "sustainable production" is attached greatest attention at present, with a weight of 0.3936 relative to the sustainable fashion goal. Next to it is "sustainable design", with the weight of 0.2816 . "Sustainable sale" is considered least important among the five guidelines, with a mere weight of 0.0771 . It is therefore considered true that production and design are currently at the core of enterprises' efforts to pursue sustainable fashion. Of specific indicators, "materials utilization" has the largest weight of 0.3453 among all indicators under sustainable design; "share of suppliers selected based on environmental standards" has the largest weight of 0.3111 among all indicators under sustainable procurement; "energy-saving equipment utilization" enjoys the greatest weight of 0.2289 among all indicators under sustainable production; the indicators "share of green transportation means" and "packaging materials re-utilization" both seize the first place in the ranking of weights for indicators under sustainable sale, with their weights standing at 0.3545 respectively; all the three indicators under sustainable recycling have the same weight of 0.3333 . It is therefore safe to conclude that raising the materials utilization rate, selecting suppliers complying with environmental 
requirements, and conserving energy and reducing consumption are priority issues enterprises need to heed in seeking sustainable development.This paper formulates an evaluation indicator system for sustainable fashion from enterprises' point of view, covering the five links in the lifecycle of fashion products; it does not cover the sustainable consumption aspect from the consumers' perspective. Hopefully, other scholars will make even more comprehensive research on the sustainable fashion indicator system in the future.

Table 3. Calculation results for the sustainable design matrix $\mathrm{C}_{2}-\mathrm{P}$

\begin{tabular}{|c|c|c|c|c|c|c|c|c|c|}
\hline & A1 & A2 & A3 & A4 & Mi & $\omega_{i}$ & $\varpi_{i}$ & Weight sum & Approximate $\lambda$ \\
\hline A1 & 1 & 2 & 2 & 1 & 4.0000 & 1.4142 & 0.3453 & 1.4106 & 4.0855 \\
\hline A2 & $1 / 2$ & 1 & 1 & 1 & 0.5000 & 0.8409 & 0.2053 & 0.8274 & 4.0313 \\
\hline A3 & $1 / 2$ & 1 & 1 & 1 & 0.5000 & 0.8409 & 0.2053 & 0.8274 & 4.0313 \\
\hline A4 & 1 & 1 & 1 & 1 & 1.0000 & 1.0000 & 0.2441 & 1.0000 & 4.0960 \\
\hline & & & & & $\sum$ & 4.0960 & & $\lambda \max$ & 4.0604 \\
\hline
\end{tabular}

Table 4. Calculation results for the sustainable procurement matrix $\mathrm{C}_{3}-\mathrm{P}$

\begin{tabular}{|c|c|c|c|c|c|c|c|c|c|}
\hline & B1 & B2 & B3 & B4 & Mi & $\omega_{1}$ & $\varpi_{i}$ & Weight sum & Approximate $\lambda$ \\
\hline B1 & 1 & 1 & 1 & 2 & 2.0000 & 1.1892 & 0.2810 & 1.1270 & 4.0103 \\
\hline B2 & 1 & 1 & 1 & 3 & 3.0000 & 1.3161 & 0.3110 & 1.2539 & 4.0319 \\
\hline B3 & 1 & 1 & 1 & 2 & 2.0000 & 1.1892 & 0.2810 & 1.1270 & 4.0103 \\
\hline B4 & $1 / 2$ & $1 / 3$ & $1 / 2$ & 1 & 0.0833 & 0.5373 & 0.1270 & 0.5116 & 4.0299 \\
\hline & & & & & $\sum$ & 4.0960 & & $\lambda \max$ & 4.0604 \\
\hline
\end{tabular}

Table 5. Calculation results for the sustainable production matrix $\mathrm{C}_{4}-\mathrm{P}$

\begin{tabular}{|c|c|c|c|c|c|c|c|c|c|}
\hline & $\mathrm{C} 1$ & $\mathrm{C} 2$ & $\mathrm{C} 3$ & $\mathrm{C} 4$ & $\mathrm{C} 5$ & $\mathrm{Mi}$ & $\omega_{1}$ & $\varpi_{\mathrm{i}}$ & Weight sum \\
\hline $\mathrm{C} 1$ & 1 & 1 & 1 & 1 & 1 & 1.0000 & 1.0000 & 0.1992 & 1.0000 \\
\hline $\mathrm{C} 2$ & 1 & 1 & $1 / 2$ & 1 & 1 & 0.5000 & 0.8706 & 0.1734 & 0.8858 \\
\hline $\mathrm{C} 3$ & 1 & 2 & 1 & 1 & 1 & 2.0000 & 1.1487 & 0.2289 & 1.1734 \\
\hline $\mathrm{C} 4$ & 1 & 1 & 1 & 1 & 1 & 1.0000 & 1.0000 & 0.1992 & 1.0000 \\
\hline $\mathrm{C} 5$ & 1 & 1 & 1 & 1 & 1 & 1.0000 & 1.0000 & 0.1992 & 1.0000 \\
\hline
\end{tabular}

Table 6. Calculation results for the sustainable sale matrix $\mathrm{C}_{5}-\mathrm{P}$

\begin{tabular}{|c|c|c|c|c|c|c|c|c|c|}
\hline & $\mathrm{D} 1$ & $\mathrm{D} 2$ & $\mathrm{D} 3$ & $\mathrm{D} 4$ & $\mathrm{Mi}$ & $\omega_{1}$ & $\varpi_{\mathrm{i}}$ & Weight sum & Approximate $\lambda$ \\
\hline $\mathrm{D} 1$ & 1 & 1 & 2 & 3 & 6.0000 & 1.5651 & 0.3545 & 1.4217 & 4.0103 \\
\hline $\mathrm{D} 2$ & 1 & 1 & 2 & 3 & 6.0000 & 1.5651 & 0.3545 & 1.4217 & 4.0103 \\
\hline $\mathrm{D} 3$ & $1 / 2$ & $1 / 2$ & 1 & 1 & 0.2500 & 0.7071 & 0.1602 & 0.6455 & 4.0299 \\
\hline $\mathrm{D} 4$ & $1 / 3$ & $1 / 3$ & 1 & 1 & 0.1111 & 0.5774 & 0.1308 & 0.5273 & 4.0319 \\
\hline & & & & & $\sum$ & 4.4146 & & $\lambda \max$ & 4.0206 \\
\hline
\end{tabular}

Table 7. Calculation results for the sustainable recycling matrix $\mathrm{C}_{7}-\mathrm{P}$

\begin{tabular}{|c|c|c|c|c|c|c|c|c|}
\hline & E1 & E2 & E3 & Mi & $\omega_{1}$ & $\varpi_{i}$ & Weight sum & Approximate $\lambda$ \\
\hline E1 & 1 & 1 & 1 & 1.0000 & 1.0000 & 0.3333 & 1.0000 & 3.0000 \\
\hline E2 & 1 & 1 & 1 & 1.0000 & 1.0000 & 0.3333 & 1.0000 & 3.0000 \\
\hline E3 & 1 & 1 & 1 & 1.0000 & 1.0000 & 0.3333 & 1.0000 & 3.0000 \\
\hline & & & & $\sum$ & 3.0000 & & $\lambda \max$ & 3.0000 \\
\hline
\end{tabular}


Table 8. Consistency test results for single hierarchies

\begin{tabular}{|c|c|c|c|c|c|c|}
\hline & C1-P & C2-P & C3-P & C4-P & C5-P & C6-P \\
\hline CI & 0.0243 & 0.0201 & 0.0069 & 0.0145 & 0.0069 & 0.0000 \\
\hline RI & 1.1200 & 0.8900 & 0.8900 & 1.1200 & 0.8900 & 0.5200 \\
\hline CR & 0.0217 & 0.0226 & 0.0077 & 0.0130 & 0.0077 & 0.0000 \\
\hline
\end{tabular}

Table 9. Weights of evaluation indicators for sustainable fashion

\begin{tabular}{|c|c|c|c|c|}
\hline Goal level & Guideline level & Level 1 weight & Indicator level & Level 2 weight \\
\hline \multirow{20}{*}{ 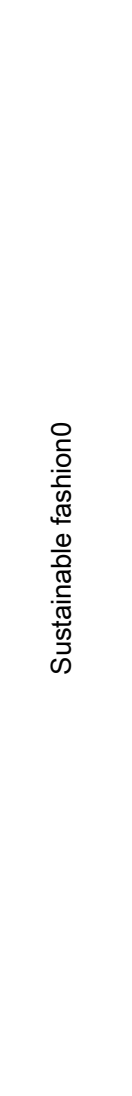 } & \multirow{4}{*}{ Sustainable design $(A)$} & \multirow{4}{*}{0.2816} & Materials utilization (A1) & 0.3453 \\
\hline & & & Processability (A2) & 0.2053 \\
\hline & & & Average service life (A3) & 0.2053 \\
\hline & & & Degradability (A4) & 0.2441 \\
\hline & \multirow{4}{*}{ Sustainable procurement (B) } & \multirow{4}{*}{0.1239} & Share of environment-friendly materials (B1) & 0.2810 \\
\hline & & & $\begin{array}{l}\text { Share of suppliers selected based on } \\
\text { environmental standards (B2) }\end{array}$ & 0.3110 \\
\hline & & & Transparency of procurement (B3) & 0.2810 \\
\hline & & & Recognition of supplier's greening (B4) & 0.1270 \\
\hline & \multirow{5}{*}{ Sustainable production (C) } & \multirow{5}{*}{0.3936} & Waste water produced (C1) & 0.1992 \\
\hline & & & GHG emissions (C2) & 0.1734 \\
\hline & & & Energy-saving equipment utilization (C3) & 0.2289 \\
\hline & & & Energy consumption reduced (C4) & 0.1992 \\
\hline & & & Water use reduced (C5) & 0.1992 \\
\hline & \multirow{4}{*}{ Sustainable sale (D) } & \multirow{4}{*}{0.0771} & Share of green transportation means (D1) & 0.3545 \\
\hline & & & Packaging materials re-utilization (D2) & 0.3545 \\
\hline & & & Share of sustainable products developed (D3) & 0.1602 \\
\hline & & & Brand recognition (D4) & 0.1308 \\
\hline & \multirow{3}{*}{ Sustainable recycling $(E)$} & \multirow{3}{*}{0.1239} & Used products re-utilization (E1) & 0.3333 \\
\hline & & & $\begin{array}{l}\text { Overall re-utilization of waste water, gas and } \\
\text { materials (E2) }\end{array}$ & 0.3333 \\
\hline & & & Harm-free waste disposal cost (E3) & 0.3333 \\
\hline
\end{tabular}

\section{REFERENCES}

[1] YANG Taosheng. United Nations conference: How can the fashion industry, "the second largest water user across the world", solve sustainability and environmental pollution problem? [EB/OL]. https://luxe.co/post/78004, 2018-03-06.

[2] Jung, S.\&Jin, B.A theoretical investigation of slow fashion: sustainable future of the apparel industry[J]. International Journal of Consumer Studies, 2014(5): 510-519.

[3] Niinimäki K. \& Koskinen. I love this dress, it makes me feel beautiful! Empathic knowledge in sustainable design [J]. The Design Journal, 2011(2): (165-186).

[4] JIA Shujie. Sustainable fashion - fashion restructuring and reuse design research [D]. Beijing Institute of Fashion Technology, 2018.
[5] Jørgensen M.S., \& Jensen, C.L. The shaping of environmental impacts from Danish production and consumption of clothing [J]. Ecological Economics, 2012: 164-173.

[6] Željko STEVIĆ, Marko VASILJEVIĆ. Evaluation of suppliers under uncertainty: a multiphase approach based on fuzzy AHP and fuzzy EDAS [J]. Transport, 2019(34): 52-66.

[7] XUE Yang. Green production performance evaluation for textile enterprises based on grey relation analysis method [D]. Xi'an Polytechnic University, 2012.

[8] ZHU Mingyang \& LIN Zihua. Conceptualization of sustainable business models and outlook on its research [N]. Journal of Shanghai University of International Business and Economics, 2015(2). 